Short Communication

\title{
Electrochemical Behavior of Graphene/ZnO Nanofllowers Synthesized by an Efficient and Facile Two-Step Technique
}

\author{
Yu Zhang ", Guangjie Liu, Fanhua Yu \\ Department of Computer Science and Technology, Changchun Normal University, Changchun \\ 130032, China \\ *E-mail: zhangy234shelly@gmail.com,
}

doi: $10.20964 / 2019.07 .78$

Received: 31 March 2019 / Accepted: 1 May 2019 / Published: 10 June 2019

\begin{abstract}
An efficient and simple route was advanced to uniformly synthesize graphene/ $\mathrm{ZnO}$ nanofllowers and an electrochemical impedance spectroscopy (EIS) technique was used to investigate the electrical properties. X-ray diffraction patterns indicated a broad and strong peak at $26^{\circ}$ value, which conformed with the graphene (002) plane. A very strong Raman band appeared at 1,594 and $1,358 \mathrm{~cm}^{-1}$, that corresponded to the independent $\mathrm{G}$ and $\mathrm{D}$ bands, respectively. The photoluminescence results show that the graphene/ $\mathrm{ZnO}$ nanostructures has a lower electrons/holes recombination rate under UV light irradiation, that may be attributed to graphene sheets in graphene/ZnO nanoflowers becoming the separation mechanisms of the photogenerated electrons/holes. Cyclic voltammetry plots indicate approximately rectangular shape, showing perfect supercapacitive behavior. The charge transfer resistance in the graphene/ $\mathrm{ZnO}$ nanoflower electrode is $175 \mathrm{k} \Omega$, which is considerably smaller than those of $\mathrm{ZnO}$ nanostructures $(684 \mathrm{k} \Omega)$ electrode, demonstrating the better conductivity in the graphene/ZnO nanoflower electrode. The graphene/ $\mathrm{ZnO}$ nanoflowers showed excellent photocatalytic activity for the degradation of MB under the visible light which can be ascribed to the high absorption intensity of graphene/ $\mathrm{ZnO}$ nanoflowers in visible light region.
\end{abstract}

Keywords: Graphene/ZnO nanofllowers; Electrochemical impedance spectroscopy; Cyclic voltammetry; Photoluminescence spectroscopy; Photocatalytic activity

\section{$\underline{\text { FULL TEXT }}$}

(C) 2019 The Authors. Published by ESG (www.electrochemsci.org). This article is an open access article distributed under the terms and conditions of the Creative Commons Attribution license (http://creativecommons.org/licenses/by/4.0/). 